\title{
Effect of Microstructure on the Yield Ratio and Low Temperature Toughness of Linepipe Steels
}

\author{
Y. M. KIM, S. K. KIM, ${ }^{1)}$ Y. J. LIM"2) and N. J. KIM \\ Department of Materials Science and Engineering and Center for Advanced Aerospace Materials, Pohang University of \\ Science and Technology, Pohang 790-784, Korea. 11$)$ POSLab, Gwangyang, Korea. 2) Quality Technology Dept. \\ POSCO, Pohang, 790-360 Korea.
}

(Received on May 22, 2002; accepted in final form on September 29, 2002)

\begin{abstract}
The present study aims at elucidating the effects of microstructural features on the yield ratio and toughness of high strength linepipe steels. The main emphasis has been placed on understanding the effects of constituents on the properties. Several alloy systems with different constituents, i.e. ferrite-pearlite steels, ferrite steels with acicular ferrite as second phase, acicular ferrite steels with ferrite as second phase, and bainite steels, have been investigated. Experimental results show that while the refinement of ferrite grain size improves both yield strength and low temperature toughness of ferrite-base steels, it increases the yield ratio. Modification of matrix from ferrite to acicular ferrite or bainite results in improvements in both yield strength and yield ratio. However, bainite steels have worse low temperature toughness (i.e., higher DBTT) than the other types of steels. It has been shown that the low temperature toughness of acicular ferrite steels can be improved by the introduction of polygonal ferrite as a second phase. This is mainly due to the refinement of effective grain size by the introduction of second phases. The relationship between the yield ratio and work hardening exponent has also been established using the Swift equation. Based on the results, the optimum microstructure for a better combination of strength, toughness and yield ratio is suggested to be the one having second phase of polygonal ferrite in an acicular ferrite or bainite matrix.
\end{abstract}

KEY WORDS: steel; DBTT; yield ratio; toughness.

\section{Introduction}

Linepipe steels, which transport oil and gas, should have high strength, high toughness, excellent corrosion resistance and superior weldability. ${ }^{1-3)}$ The current demand is towards the larger-diameter and higher-pressure linepipes to improve the efficiency of transmission, resulting in more stringent specifications for the linepipe steels. In addition to the above mentioned properties, the steels should have low yield ratio (yield strength/tensile strength) for the safety concern. The lower yield ratio means the higher resistance to deformation from yielding to plastic instability, ${ }^{4,5)}$ preventing the sudden decrease in the strength. According to the engineering specifications, API X-70 steels should have the yield strength higher than $480 \mathrm{MPa}$, impact energy larger than $100 \mathrm{~J}$ at $-40^{\circ} \mathrm{C}$ and the yield ratio smaller than $85 \%$. It has been shown in the previous study that the achievement of low yield ratio (around 80\%) and high toughness (ductile-brittle transition temperature of around $-100^{\circ} \mathrm{C}$ ) is possible in the $440 \mathrm{MPa}$ grade $\mathrm{C}-\mathrm{Mn}$ steel by controlling the thermomechanical process. ${ }^{6}$ However, it becomes more difficult to maintain adequate values of yield ratio and toughness as strength increases to a higher level. The basic difficulty in optimizing these properties comes from the fact they are often inversely correlated, i.e. an increase in the strength is achieved at the expense of the yield ratio and toughness, and vice versa. Therefore to develop the high performance linepipe steels, the individual effect of microstructural features on these properties should be clearly understood.

One of the ways of decreasing the yield ratio is the utilization of hard second phase in the microstructure. Numerous studies on so-called dual phase steels showed that these steels have low yield ratio due to the presence of hard martensite or bainite in soft ferrite matrix. ${ }^{7,8)}$ Shikanai et al., ${ }^{9)}$ analyzed the relationship between the volume fraction and morphology of second phase and the yield ratio by finite element method (FEM) and reported that the steel should have soft matrix with around $50 \%$ volume fraction of hard second phase to obtain low yield ratio. It has also been suggested that the larger difference in the strength between the two phases is more desirable to obtain low yield ratio. ${ }^{9,10)}$ However these dual phase steels generally have low yield strengths which do not meet the property requirement for X-70 linepipe steels. Moreover the large difference in the strength between the two phases might have a deleterious effect on toughness since cracks can easily nucleate at the hard second phase particles at low temperatures. Recently, more emphasis is placed on developing acicular ferrite or bainite base steels for linepipe applications. ${ }^{1-13)}$ However, the toughness of these steels is often disappointing. Therefore new microstructures are needed to obtain the adequate combinations of strength, toughness and yield ratio. 
Table 1. Chemical compositions of the steels used in the present study (mass\%).

\begin{tabular}{cccccccccccc}
\hline Steel & $\mathrm{C}$ & $\mathrm{Mn}$ & $\mathrm{Si}$ & $\mathrm{Cr}$ & $\mathrm{Mo}$ & $\mathrm{Ni}$ & $\mathrm{Nb}$ & $\mathrm{Ti}$ & $\mathrm{P}$ & $\mathrm{S}$ & $\mathrm{B}$ \\
\hline $\mathrm{A}$ & 0.08 & 1.51 & 0.20 & - & - & - & 0.05 & 0.02 & 0.002 & 0.003 & - \\
$\mathrm{B}$ & 0.06 & 1.22 & 0.26 & - & - & - & 0.05 & 0.02 & 0.004 & 0.003 & - \\
$\mathrm{C}$ & 0.06 & 1.22 & 0.26 & - & 0.29 & - & 0.05 & 0.02 & 0.004 & 0.003 & - \\
$\mathrm{D}$ & 0.06 & 1.21 & 0.26 & - & 0.47 & - & 0.05 & 0.02 & 0.004 & 0.003 & - \\
$\mathrm{E}$ & 0.06 & 1.24 & 0.26 & 0.19 & 0.30 & 0.62 & 0.05 & 0.02 & 0.004 & 0.003 & - \\
$\mathrm{F}$ & 0.06 & 1.20 & 0.26 & - & 0.47 & - & 0.05 & 0.02 & 0.004 & 0.003 & 0.0015 \\
$\mathrm{G}$ & 0.02 & 1.55 & 0.16 & - & 0.49 & 0.21 & 0.05 & 0.02 & 0.002 & 0.003 & 0.0025 \\
\hline
\end{tabular}

Table 2. Rolling conditions used for the production of the steels.

\begin{tabular}{|c|c|c|c|c|c|c|c|c|c|}
\hline \multirow{2}{*}{$\begin{array}{l}\begin{array}{c}\text { Rolling } \\
\text { condition }\end{array} \\
\text { Steel }\end{array}$} & \multicolumn{4}{|c|}{$\begin{array}{l}70 \mathrm{~mm} \stackrel{\text { Pass }}{\longrightarrow} 51 \mathrm{~mm}(27.1 \%) \stackrel{\text { Pass } 2}{\longrightarrow} \\
31 \mathrm{~mm}(16.2 \%) \stackrel{\text { Pass } 5}{\longrightarrow} 27 \mathrm{~mm}(12.9 \%)\end{array}$} & $\begin{array}{l}43 \mathrm{~mm}( \\
\text { Pass 6 } \\
\end{array}$ & $.7 \%) \stackrel{\mathrm{Pa}}{23 \mathrm{~mm}(12}$ & \multicolumn{3}{|c|}{$\begin{array}{l}37 \mathrm{~mm}(14 \%) \stackrel{\text { Pass } 4}{\longrightarrow} \\
\text { \%) } \stackrel{\text { Pass } 7}{\longrightarrow} 20 \mathrm{~mm}(15.3 \%)\end{array}$} \\
\hline & $\begin{array}{c}\text { Pass } 1 \\
\left({ }^{\circ} \mathrm{C}\right)\end{array}$ & $\begin{array}{c}\text { Pass } 2 \\
\left({ }^{\circ} \mathrm{C}\right)\end{array}$ & $\begin{array}{c}\text { Pass } 3 \\
\left({ }^{\circ} \mathrm{C}\right)\end{array}$ & $\begin{array}{c}\text { Pass } 4 \\
\left({ }^{\circ} \mathrm{C}\right)\end{array}$ & $\begin{array}{c}\text { Pass } 5 \\
\left({ }^{\circ} \mathrm{C}\right)\end{array}$ & $\begin{array}{c}\text { Pass } 6 \\
\left({ }^{\circ} \mathrm{C}\right)\end{array}$ & $\begin{array}{l}\text { FRT } \\
\left({ }^{\circ} \mathrm{C}\right)\end{array}$ & $\begin{array}{l}\mathrm{CT} \\
\left({ }^{\circ} \mathrm{C}\right)\end{array}$ & $\begin{array}{c}\mathrm{CR} \\
\left({ }^{\circ} \mathrm{C} / \mathrm{s}\right)\end{array}$ \\
\hline $\mathrm{A} 1$ & \multirow{3}{*}{1150} & \multirow{3}{*}{1100} & \multirow{3}{*}{1050} & \multirow{3}{*}{950} & \multirow{3}{*}{930} & \multirow{3}{*}{890} & 870 & 670 & 26 \\
\hline A4 & & & & & & & 870 & 600 & 37 \\
\hline A5 & & & & & & & 870 & 530 & 33 \\
\hline $\mathrm{A} 2$ & \multirow{2}{*}{1150} & \multirow{2}{*}{1100} & \multirow{2}{*}{1050} & \multirow{2}{*}{950} & \multirow{2}{*}{920} & \multirow{2}{*}{870} & 750 & 600 & 12 \\
\hline $\mathrm{A} 3$ & & & & & & & 750 & 530 & 15 \\
\hline $\begin{array}{l}\text { Rolling } \\
\text { condition }\end{array}$ & \multicolumn{9}{|c|}{$\begin{array}{l}70 \mathrm{~mm} \stackrel{1150^{\circ} \mathrm{C}}{\longrightarrow} 60 \mathrm{~mm}(14.3 \%) \stackrel{1050^{\circ} \mathrm{C}}{\longrightarrow} 50 \mathrm{~mm}(16.7 \%) \stackrel{900^{\circ} \mathrm{C}}{\longrightarrow} 42 \mathrm{~mm}(16 \%) \stackrel{850^{\circ} \mathrm{C}}{\longrightarrow} \\
30 \mathrm{~mm}(28.6 \%) \stackrel{845^{\circ} \mathrm{C}}{\longrightarrow} 20 \mathrm{~mm}(33.3 \%) \stackrel{830^{\circ} \mathrm{C}}{\longrightarrow} 13 \mathrm{~mm}(35 \%)\end{array}$} \\
\hline Steel & \multicolumn{3}{|c|}{ FRT $\left({ }^{\circ} \mathrm{C}\right)$} & \multicolumn{3}{|c|}{$\mathrm{CT}\left({ }^{\circ} \mathrm{C}\right)$} & \multicolumn{3}{|c|}{$\mathrm{CR}\left({ }^{\circ} \mathrm{C} / \mathrm{s}\right)$} \\
\hline $\begin{array}{c}\mathrm{B}, \mathrm{C}, \mathrm{D}, \\
\mathrm{E}, \mathrm{F}\end{array}$ & \multirow{4}{*}{\multicolumn{3}{|c|}{830}} & \multicolumn{3}{|c|}{580} & \multicolumn{3}{|c|}{15} \\
\hline G1 & & & & \multirow{3}{*}{\multicolumn{3}{|c|}{450}} & \multicolumn{3}{|c|}{4} \\
\hline $\mathrm{G} 2$ & & & & & & & \multicolumn{3}{|c|}{11} \\
\hline G3 & & & & & & & \multicolumn{3}{|c|}{17} \\
\hline
\end{tabular}

*FRT : finish rolling temperature, CT : coiling temperature, CR : cooling rate

The objective of the present study is to elucidate the effects of microstructural features on yield ratio and toughness of high strength linepipe steels. Of particular interest is the effect of constituents. Several alloy systems with different microstructural constituents, i.e. ferrite-pearlite steels, ferrite steels with acicular ferrite as second phase, acicular ferrite steels with polygonal ferrite as second phase, and bainite steels, have been chosen for this study.

\section{Experimental Procedure}

Chemical compositions of the steels used in the present study are shown in Table 1. These steels were produced in a laboratory scale and subjected to various rolling conditions to produce various microstructures. ${ }^{14-16)}$ Details of rolling procedures are shown in Table 2. Specimen blanks for tensile specimens were cut from the rolled plates in the transverse direction. Tensile specimens were round bars with $6 \mathrm{~mm}$ gage diameter and $30 \mathrm{~mm}$ gage length. Tensile tests were conducted at room temperature with a cross head speed of $9 \mathrm{~mm} / \mathrm{min}$. Yield strength of the steels showing discontinuous yielding behavior was taken at the lower yield point, while that of the other steels was taken at $0.2 \%$ offset. Reported tensile properties are the averages of at least 3 test results. Charpy V notch impact specimens (JIS No. 4) were also cut from the rolled plate in the transverse direction. Specimens were tested at temperatures ranging from -120 to $20^{\circ} \mathrm{C}$ with $20^{\circ} \mathrm{C}$ intervals after soaking for $15 \mathrm{~min}$ in the bath controlled by liquid nitrogen and alcohol.
Ductile-brittle transition temperature (DBTT) was taken as the temperature corresponding to the mid-point of the upper and lower shelf energies. Fracture surfaces of broken Charpy specimens were examined using scanning electron microscopy (SEM). Volume fraction of the constituent phases and the grain size were analyzed by using an image analyzer.

\section{Results}

\subsection{Microstructure}

Figure 1 shows the representative microstructures of the steels with various constituents. These are ferrite-pearlite steels (Fig. 1(a)), ferrite steels with acicular ferrite as second phase (Fig. 1(b)), acicular ferrite steels with polygonal ferrite as second phase (Fig. 1(c)), and bainite steels (Fig. 1(d)).

Detailed microstructural characteristics of the steels are summarized in Table 3. Ferrite grain size of the ferritepearlite steels ranges from 6.8 to $20.4 \mu \mathrm{m}$. The volume fraction of acicular ferrite in the ferrite-acicular ferrite steels varies from 9.6 to $24.1 \%$. The ferrite-acicular ferrite steels also contain a small amount of pearlite (around 2\%). The ferrite grain sizes of the ferrite-acicular ferrite steels ranges from 4.4 to $7.4 \mu \mathrm{m}$, which is generally finer than those of the ferrite-pearlite steels. The acicular ferrite-ferrite steels are characterized by the presence of fine (around $4.5 \mu \mathrm{m}$ ) polygonal ferrite grains within the elongated acicular ferrite matrix. The volume fraction of ferrite in the acic- 

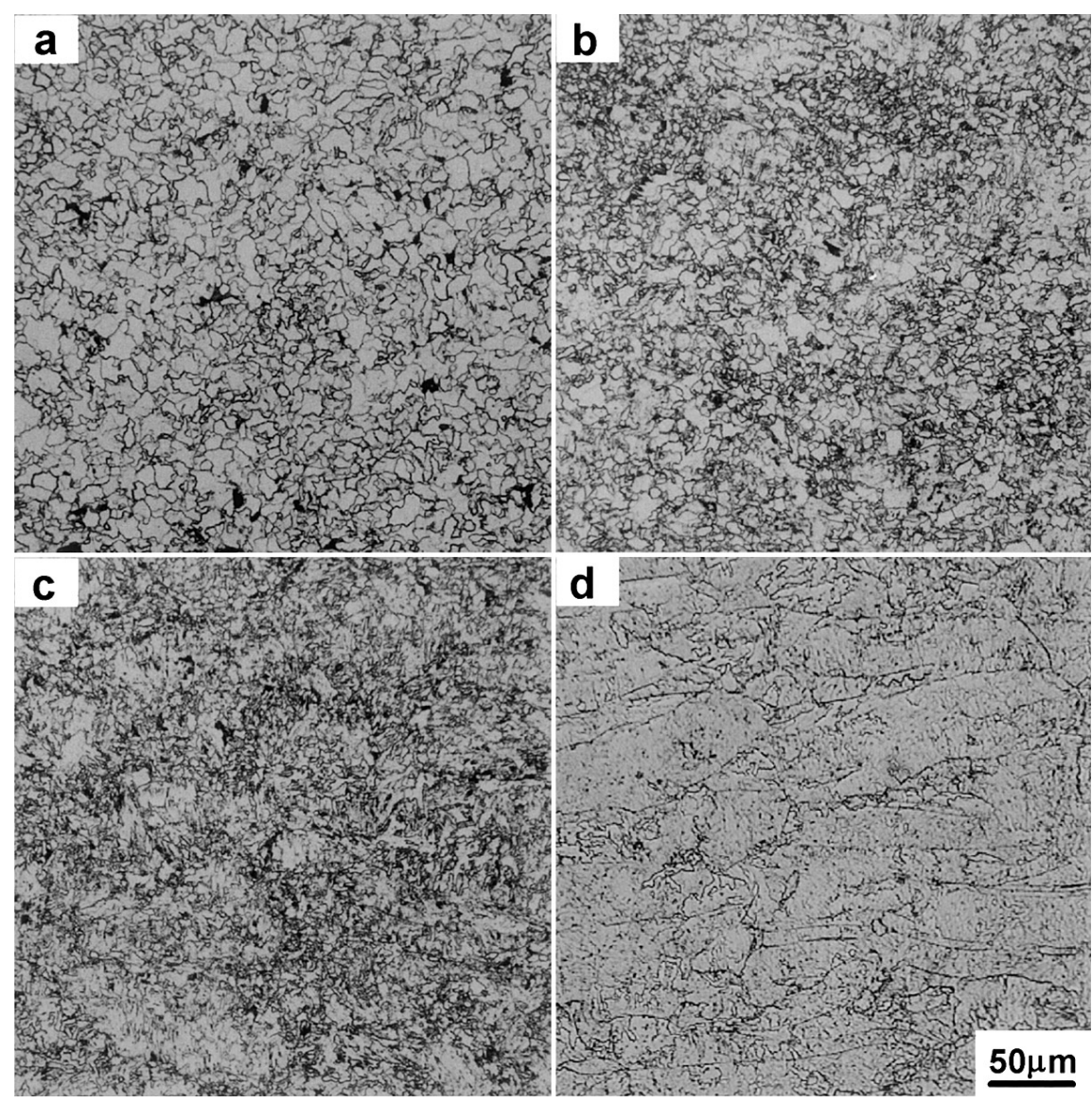

Fig. 1. Representative microstructures of the steels with various constituents; (a) ferrite-pearlite steel (B steel), (b) ferrite steel with acicular ferrite as second phase (C steel), (c) acicular ferrite steel with polygonal ferrite as second phase (D steel), and (d) bainite steel (G2 steel).

Table 3. Details of microstructural features of various steels.

\begin{tabular}{c|ccccc}
\hline \multirow{2}{*}{ Structure } & Steel & $\begin{array}{c}\text { Ferrite Grain } \\
\text { Size }(\mu \mathrm{m})\end{array}$ & \multicolumn{3}{c}{ Vol. \% of Second Phase } \\
& & Ferrite $(\%)$ & Pearlite (\%) & AF or B (\%) \\
\hline \multirow{5}{*}{ F-P } & A1 & 9.6 & 90.7 & 9.3 & - \\
& A2 & 20.4 & 91.2 & 8.8 & - \\
& A3 & 11.8 & 93.0 & 5.2 & 1.8 \\
& B & 6.8 & 98.3 & 1.7 & - \\
\hline \multirow{5}{*}{ F-AF } & A4 & 7.4 & 80.5 & 8.1 & 11.4 \\
& A5 & 7.2 & 75.9 & - & 24.1 \\
& C & 4.3 & 88.7 & 1.7 & 9.6 \\
\hline \multirow{4}{*}{ AF-F } & D & 4.6 & 5.9 & 2.1 & 92 \\
& E & 4.2 & 5.5 & 1.1 & 93.4 \\
& F & - & - & 2.2 & 97.8 \\
\hline \multirow{5}{*}{ B } & G1 & - & 3.0 & - & 97.0 \\
& G2 & - & 2.1 & - & 97.9 \\
& G3 & - & 1.8 & - & 98.2 \\
\hline
\end{tabular}

$\mathrm{F}$ : ferrite, $\mathrm{AF}$ : acicular ferrite, $\mathrm{P}$ : pearlite, $\mathrm{B}$ : bainite

ular ferrite-ferrite steels is around $6 \%$ and the inter-ferrite spacing along the rolling direction is measured to be around $16 \mu \mathrm{m}$. The bainite steels have the microstructure consisting of elongated grains, which resemble the morphology of prior austenite grains.

\subsection{Tensile Properties}

Tensile properties of the steels are listed in Table $\mathbf{4}$ along with their impact properties. It shows that the bainite steels have the highest strength followed by the acicular ferriteferrite steels, the ferrite-acicular ferrite steels and the ferrite-pearlite steels. The strength of multiphase steels is dependent on the volume fraction and strength of constituent phases as shown in previous studies. ${ }^{7-9)}$ Bainite contains a large amount of dislocations in the microstructure, which causes significant strengthening effect. Therefore, the strength of the bainite steels is the highest, while that of the ferrite-pearlite steel is the lowest. The yielding behavior changes from discontinuous yielding in ferrite-pearlite steels to quasi-continuous yielding in ferrite-acicular ferrite steels. Acicular ferrite-ferrite and bainite steels show continuous yielding behavior.

Figure 2 shows the relationship between yield strength and yield ratio of the steels. It shows that, at the same yield strength level, the bainite steels have the lowest value of yield ratio, followed by the acicular ferrite-ferrite steels, ferrite-acicular ferrite steels, and the ferrite-pearlite steels. It can also be seen in Fig. 2 that it is very difficult for the ferrite-pearlite steels to meet the tensile property specifications for X-70 grade steels (i.e., yield strength higher than $480 \mathrm{MPa}$ and yield ratio lower than $85 \%$ ). However, other types of steels can meet the specifications.

\subsection{Impact Toughness and Fracture Behavior}

DBTTs and upper shelf energies of various steels are shown in Table 4. Figure 3 shows the relationship between yield strength and DBTT of the steels. As is the case of ten- 
Table 4. Tensile and impact properties of various steels.

\begin{tabular}{ccccccc}
\hline Steel & YS (MPa) & UTS (MPa) & EL (\%) & YR (\%) & DBTT $\left({ }^{\circ} \mathrm{C}\right)$ & $\begin{array}{c}\text { Upper Shelf } \\
\text { Energy }(\mathrm{J})\end{array}$ \\
\hline A1 & 465 & 555 & 42.5 & 83.8 & -51 & 406 \\
A2 & 458 & 553 & 40.5 & 82.9 & -15 & 400 \\
A3 & 456 & 550 & 37.2 & 82.9 & -31 & 400 \\
B & 469 & 523 & 31.2 & 89.5 & -82 & 421 \\
\hline A4 & 489 & 583 & 35.0 & 83.9 & -40 & 371 \\
A5 & 508 & 582 & 36.5 & 87.3 & -25 & 349 \\
C & 543 & 618 & 25.4 & 87.9 & -79 & 305 \\
\hline D & 587 & 707 & 23.7 & 83.0 & -78 & 266 \\
E & 592 & 719 & 24.2 & 82.5 & -90 & 212 \\
F & 588 & 697 & 19.2 & 84.4 & -63 & 179 \\
\hline G1 & 575 & 718 & 15.3 & 80.2 & -28 & 272 \\
G2 & 629 & 747 & 14.7 & 84.2 & -12 & 255 \\
G3 & 653 & 757 & 11.8 & 86.2 & 3 & 258 \\
\hline
\end{tabular}

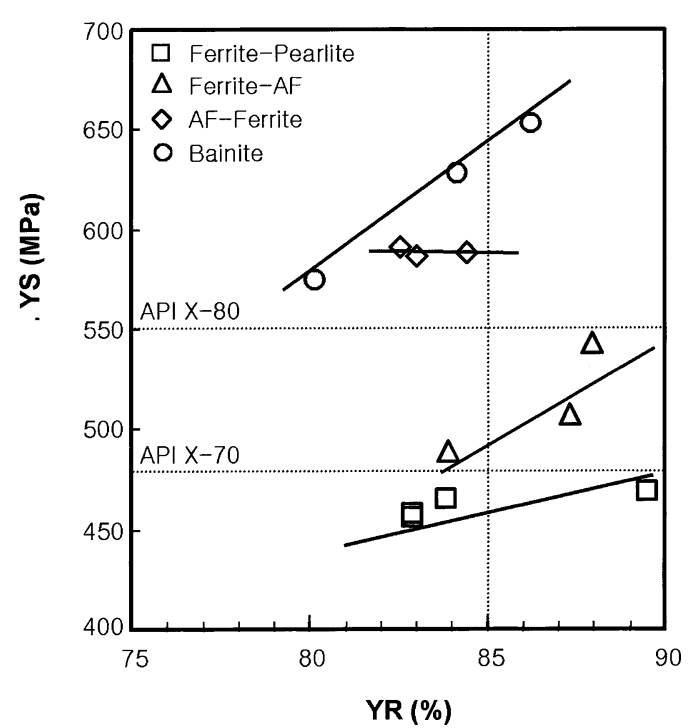

Fig. 2. Relationship between yield strength and yield ratio of various steels.

sile properties, it is difficult to make clear analyses on the effect of microstructure on the variation of DBTT since the steels have large differences in the chemical composition. However, there are rather distinctive differences in DBTTs among various microstructures, which clearly shows the effect of microstructure on DBTT. It shows that the acicular ferrite-ferrite steels have the best combinations of yield strength and DBTT. Although bainite steels have very high strength, they have poor low temperature toughness. Their DBTTs range from 3 to $-28^{\circ} \mathrm{C}$, which are much higher than the property requirement for X-70 grade API steels. Moreover, these steels have much lower shelf energies at all test temperatures than the other types of steels.

Representative SEM fractographs of the steels with various microstructures are shown in Fig. 4. Fractographs were taken from the specimens broken at below the respective DBTTs and hence all fractographs show the cleavage fracture surface. As expected from the impact properties, fracture surface shows large differences in the size of cleavage facets depending on the microstructure. It shows that the ferrite-base, i.e., ferrite-pearlite and ferrite-acicular ferrite, steels have the cleavage facets on the scale of ferrite grain

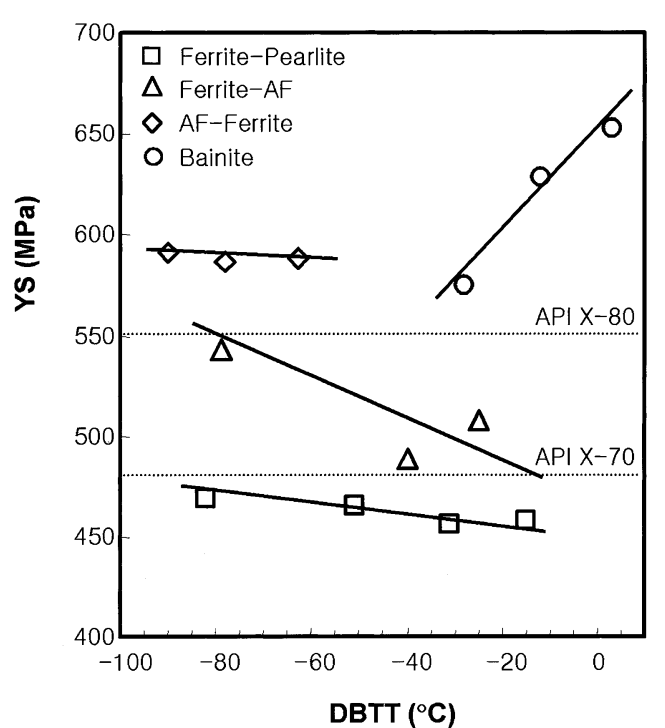

Fig. 3. Relationship between yield strength and DBTT of various steels.

size, which is the smallest among all the steels (Fig. 4(a)). The bainite steels have the largest cleavage facets on the scale of prior austenite grain size along the elongated direction (Fig. 4(d)).

\section{Discussion}

\subsection{Yield Ratio}

As shown above, the steels show different combinations of yield strength and yield ratio depending on their microstructural constituents. In general, it can be said that the steel with lower yield strength has the lower value of yield ratio. However, such statement may lead to a wrong conclusion since yield ratio is a function of not only yield strength but also work hardening rate. In the case of ferrite-pearlite steels, reducing the ferrite grain size increases the yield strength with an accompanying increase in yield ratio. Moreover, reducing the ferrite grain size decreases the work hardening rate, which has an additional effect on increasing yield ratio. Similar behavior is operating in the steels having a second phase of acicular ferrite instead of pearlite. However, modification of matrix from ferrite to acicular 

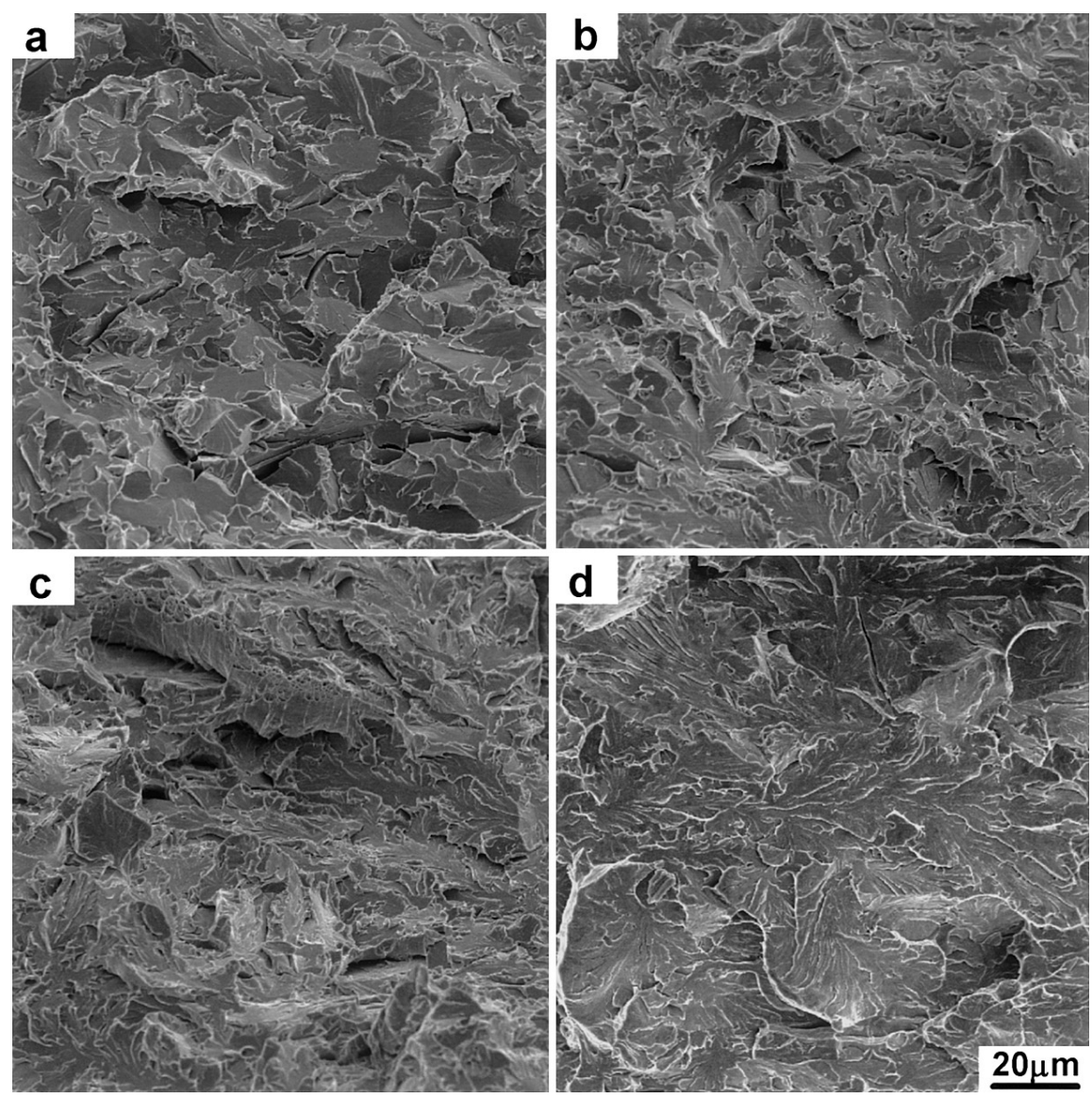

Fig. 4. SEM fractographs of broken Charpy impact specimens; (a) ferrite-pearlite steel (B steel), (b) ferrite-acicular ferrite steel (C steel), (c) acicular ferrite-ferrite steel (D steel), and (d) bainite steel (G2 steel).

ferrite results in increase in yield strength and decrease in yield ratio. The existence of large density of mobile dislocations in the acicular ferrite results in continuous yielding and high work hardening rate. ${ }^{17)}$ When the load is applied, acicular ferrite matrix shows a large response to strain hardening, resulting in a high ultimate tensile strength. The net result is that the steels with acicular ferrite matrix can have lower values of yield ratio than the steels with polygonal ferrite matrix. The steels with bainite matrix have even higher work hardening rate than those with acicular ferrite matrix. Therefore. The bainite-base steels can have lower yield ratio than the acicular ferrite-base steels at the same strength level.

As discussed above, it is impossible to make a general statement on which microstructure has the lowest value of yield ratio since yield ratio is actually a function of both yield strength and work hardening rate. To have a better understanding of the effect of the microstructure on yield ratio, stress-strain behavior of the steels has been analyzed using the Holloman equation and the Swift equation. ${ }^{14,15)}$ It has been shown that the Holloman equation cannot describe the stress-strain behavior of steels since it underestimates the strength at low strain levels. However, the Swift equation can adequately describe the stress-strain behavior of steels and the relationship between the yield ratio and work hardening exponent has been derived as follows ${ }^{14,15)}$;

$$
\mathrm{YR}=\frac{S_{\mathrm{y}}}{S_{\mathrm{u}}}=\frac{\left(b+\ln \left(1+e_{\mathrm{y}}\right)\right)^{N}}{\left(1+e_{\mathrm{y}}\right)} \frac{\exp (N-b)}{N^{N}} \ldots \ldots . .
$$

Table 5. Values of $b$ in Swift equation and critical work hardening exponent $\left(N^{*}\right)$ for achieving the yield ratio of 0.85 .

\begin{tabular}{ccc}
\hline Structure & $\mathrm{b}$ & $\mathrm{N}^{*}$ \\
\hline Ferrite-Pearlite & 0.03 & 0.1738 \\
Ferrite-Acicular Ferrite & 0.03 & 0.1738 \\
Acicula Ferrite-Ferrite & 0.01 & 0.1175 \\
Bainite & 0.002 & 0.0796 \\
\hline
\end{tabular}

where $S_{\mathrm{y}}$ is the yield strength, $S_{\mathrm{u}}$ is the ultimate tensile strength, $b$ is the additive strain constant, $e_{\mathrm{y}}$ is the engineering strain at yield strength (usually 0.002 ), and $N$ is the work hardening exponent.

The linear relationship has been established between $\ln (\sigma)$ and $\ln \left(\varepsilon_{\mathrm{P}}+b\right)$ by setting the appropriate values of $b$ for each type of microstructure ( $\sigma$ is the true stress and $\varepsilon_{\mathrm{P}}$ is the true plastic strain). Table 5 shows the values of $b$ for each type of microstructure. The values of $b$ range from 0.002 to 0.03 , depending on the microstructure with the lowest value of $b$ associated with heavily dislocated structure. It suggests that $b$, the additive strain constant, is a function of amount of strain hardening (e.g., dislocation density) the alloy has received prior to tensile testing. Figure 5 shows the relationship between the yield ratio and work hardening exponent of various steels. The experimental results agree well with the results calculated using the above equation. It shows that the ferrite-base steels have larger work hardening exponents than the acicular ferrite- 
or bainite-base steels. Increasing the ferrite grain size increases the work hardening exponent of the ferrite-base steels, thereby decreasing the yield ratio. In the case of acicular ferrite-base steels, increasing the volume fraction of soft second phase of polygonal ferrite increases the work hardening exponents, resulting in a decrease in yield ratio. Comparing the relationship between yield ratio and work hardening exponent of the steels with similar microstructure, it shows that increasing the work hardening exponent decreases the yield ratio. However, the dependence of yield ratio with work hardening exponent varies depending on the type of structure. The steels having higher work hardening rate (e.g., bainite-base steels) have lower yield ratio than the steels having lower work hardening rate (e.g., ferrite-base steels) when compared at the same value of work hardening exponent. The critical work hardening exponent $\left(N^{*}\right)$ for achieving the yield ratio of 0.85 is also shown in Table 5. It can be seen that $N^{*}$ is the lowest for the bainitebase steels, followed by the acicular ferrite-base, and the ferrite-base steels.

\subsection{Low Temperature Toughness}

As shown in Fig. 4, the sizes of the cleavage facets are different depending on the microstructural constituents, with the smallest in ferrite-base steels and the largest in the

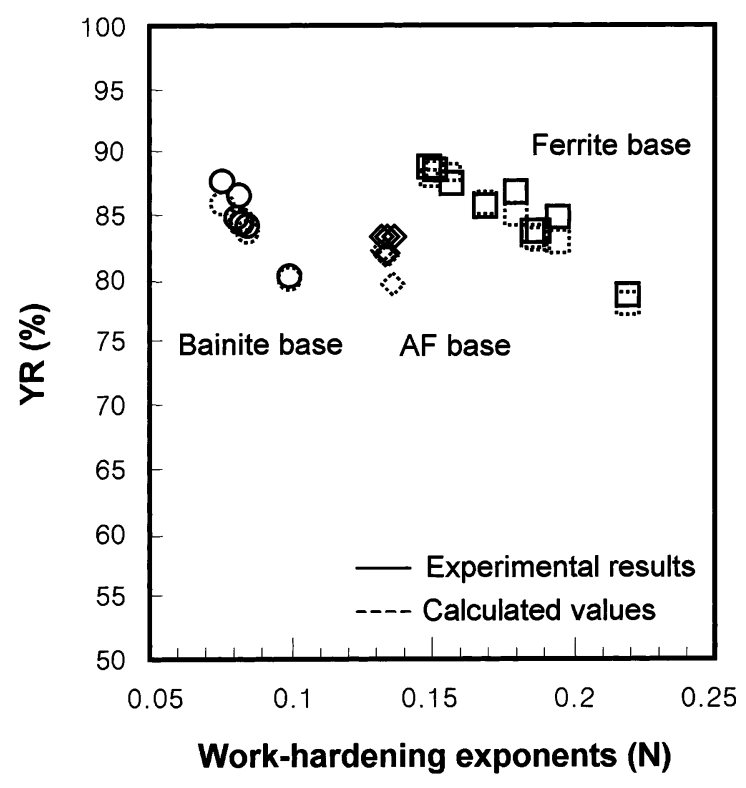

Fig. 5. Relationship between yield ratio and work hardening exponent of various steels. bainite steels. It suggests that the effective grain sizes controlling DBTT are also different depending on the microstructural constituents. In the case of ferrite-base steels, the effective grain size is the ferrite grain size. This is confirmed by the cross sectional micrography of the broken Charpy impact specimen (Fig. 6(a)) showing the change of crack propagation direction at the ferrite grain boundaries. It is well known that decreasing the ferrite grain size improves both strength and low temperature impact toughness. It can be seen in Fig. 3 that DBTT decreases from -15 to $-82^{\circ} \mathrm{C}$ with refining the ferrite grain size from 20.4 to $6.8 \mu \mathrm{m}$.

The size of the cleavage facets in bainite steels is very large. In fact, their size is about $100 \mu \mathrm{m}$ along the direction of crack propagation, which is similar to the diameter of prior austenite grains along elongated direction. This suggests that the effective grain size for the bainite steels is the prior austenite grain size. Cross sectional micrography of the broken Charpy impact specimen (Fig. 6(b)) shows that the crack propagates across the packet boundaries without changing direction, indicating that packet size is not the effective grain size for bainite steels. Although there can be several bainite packets within a prior austenite grain, packet boundaries cannot act as a barrier to cleavage crack propagation since packet boundary is low angle boundary. ${ }^{16)}$ Moreover, electron back-scatter diffraction (EBSD) analyses show the bainite packets within an austenite grains share the common cleavage planes. ${ }^{16)}$ The similar behavior has been found in full acicular ferrite steels. ${ }^{15}$ )

Although the acicular ferrite steels have high DBTTs, incorporation of polygonal ferrite as a second phase can considerably decreases the DBTTs as shown in Fig. 3. Fractography shows that the size of the cleavage facets in the acicular ferrite-ferrite steels is much smaller than that in the bainite steels (Fig. 4). The size of the cleavage facets in the acicular ferrite-ferrite steels is around $22 \mu \mathrm{m}$, which is similar to the inter-ferrite spacing. Cross sectional micrography of the broken Charpy impact specimen (Fig. 6(c)) shows that the crack changes its direction when it meets the acicular ferrite/ferrite boundaries (marked by arrow), indicating that the acicular ferrite/ferrite boundaries are the effective barriers to cleavage crack propagation. As in the case of acicular ferrite or bainite steels, packet boundaries do not act as barriers to cleavage crack propagation. Therefore, the effective grain size for the acicular ferrite-ferrite steels is inter-ferrite spacing. Mechanisms of
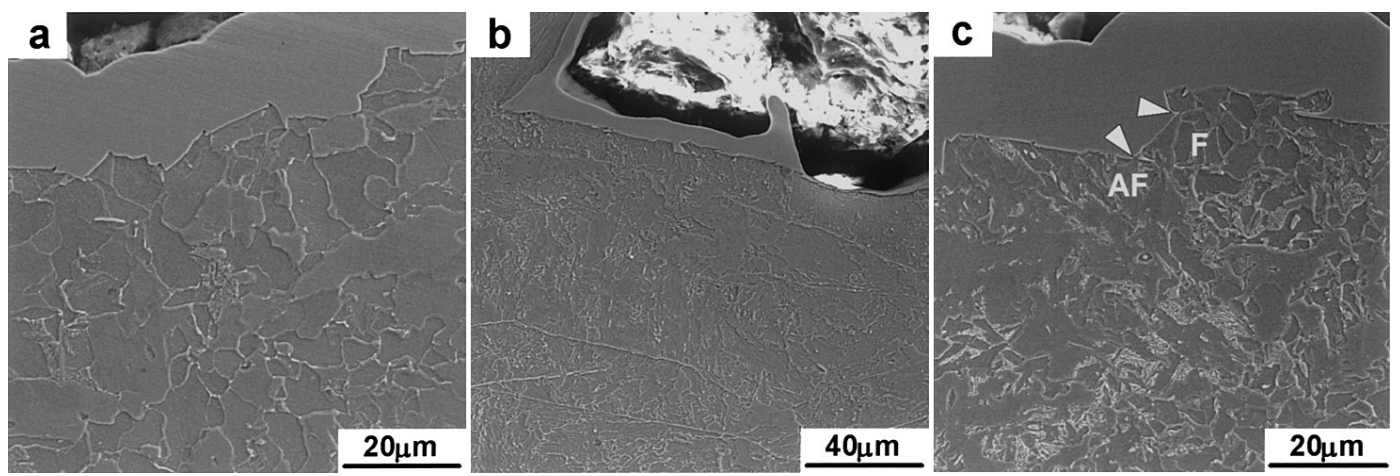

Fig. 6. Cross-sectional SEM micrography of the broken Charpy impact specimens; (a) ferrite-pearlite steel (B steel), (b) bainite steel (G2 steel), and (c) acicular ferrite-ferrite steel (D steel). 
(a)

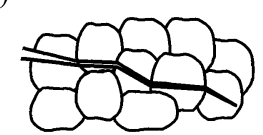

(b)

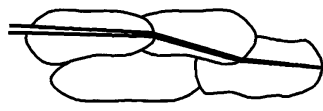

(c)

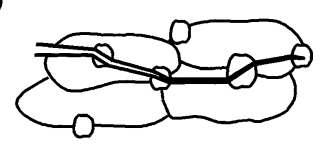

Fig. 7. Schematic drawings showing the cleavage crack propagation in various steels; (a) ferrite-base steel, (b) bainite steel, and (c) acicular ferrite-ferrite steel.

cleavage crack propagation in various steels are schematically shown in Fig. 7.

Based on the correlation of microstructure and mechanical properties, optimum microstructure for the development of high performance linepipe steels can be suggested to be the one having second phase of polygonal ferrite in an acicular ferrite or bainite matrix. The achievement of optimum combination of strength, yield ratio and DBTT is difficult in ferrite-base steels since the most effective method for improving strength and toughness, i.e., grain refinement, leads to the increase in yield ratio. On the other hand, acicular ferrite- or bainite-base steels have the advantage of higher yield strength and lower yield ratio over ferrite-base steels. The problem of poor low temperature toughness of these acicular ferrite- or bainite-base steels can be overcome by the introduction of polygonal ferrite as second phase, which reduces the effective grain size.

\section{Summary}

In the present study, the effect of microstructural features on the yield ratio and toughness of high strength linepipe steels have been investigated and the results can be summarized as follows;

(1) While the refinement of ferrite grain size is quite beneficial to the improvement of both yield strength and low temperature toughness of ferrite-base steels, it has an adverse effect on yield ratio in that it increases the yield ratio.

(2) The modification of second phase from pearlite to acicular ferrite or bainite in ferrite-base steels results in the improvement in strength without affecting DBTT. However, acceptable yield ratio has been obtained in the ferrite-acicular ferrite steels only at their lower end of strength.

(3) The modification of matrix phase from ferrite to acicular ferrite or bainite results in the improvement in strength and yield ratio. However, these steels have worse low temperature toughness (i.e., higher DBTT) than the other types of steels due to their much larger effective grain size.

(4) The introduction of polygonal ferrite as a second phase in acicular ferrite or bainite matrix considerably improves the low temperature toughness of acicular ferrite- or bainite-base steels without degrading strength and yield ratio. This is mainly due to the refinement of effective grain size by the introduction of second phase particles.

(5) The relationship between the yield ratio and work hardening exponent has been made. It shows that the dependence of yield ratio with work hardening exponent varies depending on the type of structure. The critical work hardening exponent for achieving the yield ratio of 0.85 is the lowest for the bainite-base structure, followed by the acicular ferrite-base, and the ferrite-base structure.

\section{REFERENCES}

1) N. J. Kim: J. Met., 35 (1983), 21.

2) B. L. Jones and D. L. Johnson: Proc. of an Int. Conf. Steels for Line Pipe and Pipeline Fittings, Metals Society, London, (1981), 14.

3) F. C. Kroft, W. R. Kuntz, W. T. Barrett and B. Nilson: Micro Alloying 75, Union Carbide Corp., New York, (1979), 32.

4) H. Kawamura and B. Kato: Proc. of 2nd Pacific Structural Steel Conf., Australian Institute of Steel Construction, Gold Coast, (1989), 429.

5) Y. Fukumoto: Eng. Struct., 18 (1996),786.

6) N. J. Kim and G. Thomas: Mater. Sci. Technol., 1 (1985) 32.

7) N. J. Kim and G. Thomas: Metall. Trans., 12A (1981), 483.

8) N. J. Kim and G. Thomas: Scr. Metall., 18 (1984), 817.

9) N. Shikanai, H. Kagawa and M. Kurihara: ISIJ Int., 32 (1992), 335.

10) H. Fischmeister, J.-O. Hjalmered, B. Karlsson, G. Linden and B. Sundstron: The Microstructure and Design of Alloys, Inst. of Metals and Iron \& Steel Inst., London, (1973), 621

11) A. B. Cota, R. Barbosa and D. B. Santos: J. Mater. Process. Technol., 106 (2000), 156.

12) A. K. Lis: J. Mater. Process. Technol., 106 (2000), 212.

13) P. C. M. Rodrigues, E. V. Pereloma and D. B. Santos: Mater. Sci. Eng., 283A (2000), 136.

14) S. K. Kim, Y. J. Lim, Y. M. Kim and N. J. Kim: submitted to Met. Mater. Int.

15) S. K. Kim, Y. M. Kim, Y. J. Lim and N. J. Kim: Proc. of 15th Conf. on Mechanical Behaviors of Materials, Korean Institute of Metals and Materials, Seoul, (2001), 177.

16) Y. M. Kim, S. K. Kim and N. J. Kim: "Effect of hot rolling conditions on the tensile and impact properties of ultra low carbon bainitic steels", submitted to Metall. Mater. Trans.

17) A. C. Bannister, J. Ruiz Ocejo and F. Gutierrez-Solana: Eng. Fract. Mech., 67 (2000), 547. 